\title{
PLURALIDADE SINDICAL NO CAMPO? AGRICULTORES FAMILIARES E ASSALARIADOS RURAIS EM UM CENÁRIO DE DISPUTAS'
}

\section{Everton Lazzaretti Picolotto ${ }^{\mathrm{a}}$}

aé doutor em Ciências Sociais pela Universidade Federal Rural do Rio de Janeiro (UFRRJ) e professor do Departamento de Ciências Sociais e dos Programas de Pós-Graduação em Ciências Sociais e em Extensão Rural da Universidade Federal de Santa Maria (UFSM). Santa Maria, RS, Brasil.E-mail:<everton.picolotto@ufsm.br> Orcid: 0000-0003-4199-5553

http://dx.doi.org/10.1590/0102-201238/104

\section{Introdução}

$\mathrm{O}$ sindicalismo dos trabalhadores rurais constitui a maior rede de sindicatos do Brasil e é um dos únicos ramos que tem registrado aumento de filiações. São mais de quatro mil sindicatos, cerca de cinquenta federações estaduais e três confederações nacionais. Segundo dados da Pesquisa Nacional por Amostra de Domicílios (PNAD), a taxa de sindicalização rural nas últimas décadas passou de 17\% em 1992 para $24 \%$ em 2013, enquanto a taxa de sindicalização urbana decaiu, no mesmo período, de $23 \%$ para $15 \%$ (Rodrigues, 2015). Essa estrutura, articulada historicamente pela Confederação Nacional dos Trabalhadores na Agricultura (Contag), além de robusta e com grande distribuição no país, tem vivenciado mudanças profundas desde meados da década de 1990, quando assumiu a agricultura familiar como público prioritário e conduziu certa transformação interna

\footnotetext{
1 Este artigo traz resultados do projeto "A formação do sindicalismo da agricultura familiar no Brasil e a pluralidade sindical no campo" financiado pelo Edital de Ciências Humanas e Sociais - MCTI/CNPq/MEC/CAPES, n. 22/2014.
} 
para adequar seu projeto político, passando para segundo plano outras bandeiras tradicionais, como a reforma agrária, os direitos trabalhistas e as categorias de trabalhadores rurais que as sustentavam, como os assalariados rurais, sem-terra, posseiros etc. De outra parte, tem enfrentado a concorrência de outras organizações sindicais, como a Federação dos Empregados Rurais de São Paulo (Feraesp), criada em 1989, e a Federação Nacional dos Trabalhadores na Agricultura Familiar (Fetraf-Brasil) ${ }^{2}$, inicialmente criada na região Sul, em 2001, e nacionalizada na mesma década. Ademais, outras organizações não sindicais também mobilizam trabalhadores sem-terra, pequenos agricultores e diversos grupos de populações tradicionais (extrativistas, quilombolas, pescadores artesanais e ribeirinhos), entre outros.

Ainda em meados da década de 1980 ocorreu uma "implosão" da categoria "trabalhador rural" como agregadora da representação sindical no campo (Favareto, 2006;

202 Medeiros, 1989; 2001; Novaes, 1997), acompanhada pela emergência de diversas possibilidades organizativas que romperam com a estrutura corporativa da representação sindical. Surgiram tanto alternativas externas ao universo sindical - como é caso dos Movimentos dos Trabalhadores Rurais Sem Terra (MST), dos Atingidos por Barragens (MAB) e das Mulheres Trabalhadoras Rurais (MMTR) - quanto outras que, dentro do campo sindical, apontaram para a criação de sindicatos por categorias específicas, tais como os empregados rurais, os fumicultores, os suinocultores e, mais recentemente, os agricultores familiares (Medeiros, 1989; 2001).

Pelos canais da Central Única dos Trabalhadores (CUT) formou-se uma estrutura sindical rural que se via como paralela à Contag. O Departamento Nacional dos Trabalhadores Rurais (DNTR) da CUT, fundado em 1988, foi uma iniciativa

\footnotetext{
2 No ano de 2016, a Fetraf alterou sua denominação para Confederação Nacional dos Trabalhadores na Agricultura Familiar (Contraf).
} 
ousada que procurava concretizar o programa da Central de defesa da liberdade e autonomia sindical (Rodrigues, 1990). O DNTR além de dar abrigo para sindicatos existentes e que se desgarravam da Contag também articulava oposições sindicais e novas estruturas que estavam surgindo, como a Feraesp e sindicatos regionais de pequenos produtores em Santa Catarina e no Rio Grande do Sul (Favareto, 2001; Medeiros, 1989; 2001; Picolotto, 2011).

Ainda que este primeiro ensaio de formação de uma estrutura sindical tenha sido abortado pelo acordo entre CUT e Contag em 1995, que resultaria na unificação das duas estruturas sindicais e a extinção do DNTR, problemas de diversas ordens no interior da Contag deram base para a continuidade das organizações de assalariados, como a Feraesp, novas dissidências políticas e a formação de outras estruturas sindicais específicas de agricultores familiares, como a Fetraf.

Nos últimos anos têm ocorrido expressivas mudanças no ordenamento normativo sindical rural, exigindo readequações nas organizações sindicais. Desde 2014 passou a vigorar um novo entendimento no Ministério do Trabalho e Emprego (MTE) de que podem existir duas categorias sindicais específicas dentro da categoria eclética de trabalhador rural, quais sejam: assalariados rurais e agricultores familiares. Essas duas novas possibilidades de sindicalização podem formar estruturas sindicais próprias.

Diante desse novo cenário o sindicalismo da Contag precisou se repensar nos últimos anos e tem optado por representar a agricultura familiar e dissociar a categoria dos assalariados rurais. Apoiou a formação de sindicatos de assalariados rurais, federações e a fundação da Confederação Nacional dos Trabalhadores Assalariados Rurais (Contar), em outubro de 2015. No entanto, essas mudanças também impulsionaram uma nova corrida pela busca do reconhecimento dos entes sindicais da Fetraf e da Feraesp. 
Este artigo tem por objetivo analisar as mudanças ocorridas no campo sindical com a emergência de novas organizações sindicais de agricultores familiares e de assalariados rurais e avaliar a possibilidade da configuração de uma condição de pluralidade sindical no campo brasileiro. O estudo resulta de investimentos de pesquisa realizados com financiamento do CNPq, no qual se fez uso de documentos das organizações sindicais, do MTE, de observação em eventos sindicais e de entrevistas com lideranças sindicais.

\section{Sindicalismo de trabalhadores rurais: entre 0 corporativismo e o pluralismo}

O sindicalismo brasileiro foi estruturado na década de 1930 pelo governo de Getúlio Vargas segundo uma forma corporativista de conceber as relações Estado-sociedade (Araújo, 2002; Goldin, 2013; Ladosky, 2014) - corporativismo que Schmitter (1974) chamou de "estatal ou autoritário",

204 em que as representações dos grandes interesses sociais são subordinadas à "autoridade estatal, quando não são criadas por ela” (Araújo e Tápias, 1991, p. 10). Tal corporativismo constitui a unidade dos múltiplos interesses em um único corpo de representação, e um dos seus traços característicos é a forte identificação entre Estado e sociedade, com afluências para a concentração do poder no primeiro.

Esse modelo deixou suas marcas na estrutura sindical brasileira. A primeira delas diz respeito à tutela do Estado sobre as organizações sindicais. Tal tutela foi estabelecida pela chamada investidura sindical, que significou a necessidade de reconhecimento prévio do sindicato pelo Estado, por meio da Carta Sindical. Ou seja, era o Estado que outorgava às entidades sindicais a representatividade de determinado segmento de trabalhadores e o poder de negociação com os órgãos patronais. Além disso, o Ministério do Trabalho exercia forte controle sobre a vida sindical, seja na regulação das eleições, das posses de diretorias, poder de intervenção, 
fiscalização das ações e das finanças. A segunda marca foi dada pelo estabelecimento da unicidade sindical, que instituía a existência de apenas uma organização sindical, em qualquer grau, representativa de categoria profissional ou econômica, na mesma base territorial. Por fim, a terceira marca refere-se às contribuições sindicais obrigatórias estabelecidas por lei: imposto sindical e taxa assistencial. Tais contribuições foram uma espécie de poder tributário concedido pelo Estado aos sindicatos, fazendo-os dependerem do próprio Estado e não dos trabalhadores de sua base para se financiarem (Boito Jr., 1991; Coletti, 1998; Ladosky, 2014; Pinto, 1979; Vianna, 1976).

O sindicalismo dos trabalhadores rurais foi regulamentado na década de 1960, por meio de portarias do Ministério do Trabalho que estabeleceram a representação paralela entre trabalhadores e patrões. O sindicalismo dos trabalhadores organizou-se na forma de Sindicatos dos Trabalhadores Rurais (STR) nos municípios, de Federações de Trabalhadores na Agricultura (Fetag) nos estados e da Contag, órgão sindical superior de âmbito nacional. Nessa estrutura, toda a diversidade de grupos sociais e de situações de trabalho rural foi enquadrada na categoria trabalhador rural, sejam eles assalariados, pequenos proprietários, arrendatários, posseiros, entre outros (Medeiros, 1989; 2001; Novaes, 1997; Palmeira, 1985).

Nas disputas políticas nos primeiros tempos desse sindicalismo, a opção do grupo que assumiu a direção da Contag em 1968, após um período de intervenção do regime militar, foi a de fazer um esforço político de garantir a unificação dessa diversidade contra tendências que se esboçavam nas direções quer de deslocar os pequenos produtores aos sindicatos rurais patronais, ligados à Confederação Nacional da Agricultura (CNA), quer de formação de um sindicalismo próprio de pequenos produtores (Medeiros, 2001; 2014; Palmeira, 1985) ${ }^{3}$.

\footnotetext{
3 A possibilidade formar uma terceira faixa de enquadramento sindical também aparecia nas articulações de sindicalistas do Sul do país, que não se sentiam confortáveis em uma organização hegemonizada por porta-vozes de assalariados, parceiros e posseiros,
} 
Ao trabalho político de unificação conduzido pela Contag soma-se a unificação formal desse sindicalismo consolidado com o Decreto-Lei n⿳ำ 1.166, de 15 de abril de 1971, que dispunha sobre o enquadramento e as contribuições sindicais rurais. Nele são definidos os contornos do que se deve entender por "trabalhador rural", seja empregado ou pequeno produtor, ambos abrigados no sindicalismo de trabalhadores rurais. O pequeno produtor é considerado trabalhador quando "proprietário ou não trabalhe individualmente ou em regime de economia familiar", "ainda que com ajuda eventual de terceiros", em área igual ou inferior à dimensão do módulo rural $^{4}$ da respectiva região (Brasil, 1971, n.p.). Algumas décadas depois - após muitos debates e pressão interna na Contag, vinda especialmente das federações do Sul do país, que requeriam a ampliação destas dimensões - a Lei 9.701, de 17 de novembro de 1998, ampliou o enquadramento do pequeno produtor para 206 explorações com áreas de até dois módulos rurais da respectiva região (Brasil, 1998). Ou seja, quem tiver menos do que dois módulos é considerado enquadrado para fins sindicais na categoria de trabalhador rural.

No final dos anos 1970 e início da década seguinte, emergiram novas lideranças e novas formas de encaminhar as lutas, e junto com as novas demandas desafiavam o sindicalismo contaguiano a gerar respostas. Essa situação trouxe à tona críticas ao modo de agir deste sindicalismo que, apesar de seus esforços, tinha dificuldades de dar voz e encaminhar as reivindicações de diferentes segmentos, num momento

especialmente, de lideranças nordestinas. Para superar essas divergências foi criado um programa unificador dos diferentes grupos. Segundo Francisco Urbano (dirigente da Contag nas de 1970-1990), a definição de um "Plano de Integração Nacional" estabeleceu que "temos que ter políticas para todos os grupos que nós representamos" (informação verbal, entrevista ao autor, 2016).

${ }^{4} \mathrm{O}$ módulo rural é uma medida fixada para cada região, define a propriedade familiar que absorve toda a força de trabalho da família, garantindo-lhes a subsistência e o progresso social e econômico (Lei no 4.504 , de 1964). 
em que novos atores e repertórios de ação ganhavam espaço público e novas questões surgiam. Assim, além das demandas referentes a posseiros, assalariados, pequenos agricultores, aparecia as lutas por terra pelos que a haviam perdido, dos atingidos por barragens, dos afetados pelas secas, dos que buscavam manter suas atividades tradicionais, como é o caso dos seringueiros. Demandas antigas e novas se cruzavam com os debates nacionais sobre sindicalismo e seus rumos (Picolotto e Medeiros, 2016). Esse processo vincula-se intimamente à atuação de setores da Igreja Católica ligados à Teologia da Libertação, que - por meio de um trabalho molecular nas comunidades eclesiais de base, cursos de formação, entre outras atividades - foram introduzindo novas questões e disposições, em especial entre os jovens. Surgiram as oposições sindicais que se articularam na CUT e desenvolveram uma série de críticas às formas de ação do sindicalismo contaguiano, tais como: "assistencialistas", "atrelados ao governo", "burocráticos", "conservadores” etc. Paralelamente, surgiram organizações, independentes das normas que tolhiam a ação sindical, como o MST, MAB, MMTR, entre outros (Favareto, 2001; Medeiros, 1989; Novaes, 1991).

Com esses novos atores conformava-se um "campo de forças" (Bourdieu, 2005) no âmbito da representação política com rebatimentos no sindicalismo. Enquanto o sistema Contag defendia a unidade corporativa da categoria trabalhador rural, por meio da manutenção da unicidade sindical e de seu monopólio na representação de todos os trabalhadores do campo, de outro lado, o sindicalismo rural ligado à CUT propunha liberdade e autonomia, qual seja, a possibilidade de formar novos sindicatos autônomos ao Estado, mas adequados à organização das lutas de categorias sociais específicas no campo. Fosse entre os assalariados rurais ou entre os pequenos produtores e sem terras, estimulava a diferenciação de estruturas. A postura da CUT se baseava em um ideário influenciado pelas experiências pluralista 
de vertentes socialistas e anarquistas de origem europeia e norte-americana (Goldin, 2013; Ladosky, 2014; Ricci, 2013). $\mathrm{Na}$ concepção pluralista podem conviver "vários grupos ou centros de poder, mesmo que em conflito entre si" (Bobbio, 1998, p. 928). Trata-se de uma corrente de pensamento que se opõe à concentração e unificação do poder e, no campo sindical, se opõe ao monopólio corporativista da estrutura sindical oficial. É favorável à coexistência de organizações sindicais diversas competindo entre si, segundo a lógica de um "campo" ou "mercado" político, em que os agentes competem por ideias, por interesses e pela representação de bases sociais.

O processo de democratização da sociedade brasileira ao longo dos anos 1980 e a pressão e conquistas dos movimentos sociais na Constituição de 1988 favoreceram o fortalecimento da sociedade civil diante do Estado, pulverizando os centros de representação e enfraquecendo o jugo corpo208 rativista tradicional. Deram base, por um lado, para a formação de uma expressiva pluralização dos movimentos sociais (sejam sindicais ou por fora dos canais sindicais), o que configura diversos centros de representação de interesses; o enfraquecimento da tutela estatal sobre as organizações sindicais. Por outro lado, a criação de espaços de negociação entre o Estado e as classes sociais, para onde as organizações de representação dos trabalhadores - a CUT em particular - direcionaram suas demandas e para diversos conselhos de políticas públicas, câmaras bipartites e tripartites, fóruns de debates, conferências, etc. (Alves, 2000; Cardoso, 2003; Domingues, 2007; Ladosky, 2014).

Contudo, esse fortalecimento da sociedade civil e da pluralização dos grupos e centros de representação não foi traduzido de forma direta em mudança do estatuto legal do corporativismo sindical na Constituição de 1988. Se, de um lado, a nova Carta estabeleceu que os cidadãos devem ter liberdade de organização política e sindical, de outro, em 
termos da estrutura sindical, manteve pilares fundamentais do corporativismo, como a unicidade, as contribuições sindicais obrigatórias (similar ao antigo imposto sindical) e o poder normativo da Justiça do Trabalho.

Essas ambiguidades legais deram base para que pudessem coexistir o sistema sindical da Contag e o da CUT. Os setores rurais da CUT que já haviam constituído uma Secretaria Nacional desde sua fundação, em 1984, em 1988 tomaram a iniciativa de organizar um Departamento Nacional de Trabalhadores Rurais (DNTR) e seus Departamentos Estaduais (DETR). Funcionava como uma organização sindical paralela à Contag, articuladora das diversas categorias de trabalhadores rurais, ainda que a direção política estivesse com os pequenos agricultores (Favareto, 2006; Medeiros, 2014). Mas também foi de forças cutistas abrigadas no DNTR que surgiu a iniciativa da criação de instrumentos sindicais específicos de categorias de trabalhadores, como os empregados rurais, em São Paulo. Em 16 de abril de 1989, na cidade de Jaboticabal (SP), foi lançado um manifesto de constituição de Sindicatos de Empregados Rurais (SER) e de uma Federação dos Empregados Rurais Assalariados do Estado de São Paulo (Feraesp). Nessa iniciativa, que em 1992 passava a contar com quatorze SER - especialmente na região de Ribeirão Preto - aparecia com clareza o entendimento de que "a partir da nova Constituição, o Estado perdeu seus poderes sobre o sindicato, cabendo aos trabalhadores definir sua forma de organização, desde que obedeçam os limites da Constituição" (Feraesp, 1989 apud Coletti, 1998, p. 217, grifos no original). Dentre os principais argumentos levantados para formação de sindicatos específicos de empregados rurais estava a constatação dos "conflitos de interesses" dentro dos STR, que agregavam empregados e pequenos produtores, muitos dos quais contratavam força de trabalho externas e eram chamados de "pequenos patrões" (Coletti, 1998). Os STR tinham sido "tomados" pelos "pequenos patrões", 
não eram mais vistos como um espaço de representação dos interesses próprios dos empregados.

No início da década de 1990, ambas as vertentes sindicais da CUT e da Contag passavam por certa "crise" que demandava mudanças. O sistema Contag sofria desgaste de sua forma de relação próxima ao Estado e das dificuldades de atualizar o seu projeto sindical, suas bandeiras de luta, estrutura organizativa e forma de ação sindical pautada pelos caminhos legais. No caso do DNTR/CUT, os limitadores estavam na dificuldade em firmar-se como o interlocutor perante o Estado e na sua limitada influência nacional, por possuir bases principalmente nos estados do Sul e no Pará (Favareto, 2006; Novaes, 1991). Essa crise seria um dos motivadores da unificação destas duas tradições sindicais, realizada com a aprovação da filiação da Contag à CUT durante o IV Congresso da Contag de 1995 (Picolotto, 2011).

Com esse processo de unificação formal do sindicalismo, 210 também foi adotada uma nova postura. Passa de uma postura contestatória (marcada fortemente por mobilizações de confronto e de reinvindicações da década de 1980) para outra mais propositiva (que faz mobilizações, mas que tem propostas concretas, um projeto para a agricultura e para o país), com a participação mais ativa em comissões conjuntas com órgãos do Estado para realizar estudos sobre a agricultura familiar e definir de políticas públicas para esse público (Favareto, 2006; Picolotto, 2014a). Tratava-se de um momento em que a própria CUT, enquanto Central, passava por mudanças na sua forma de relação com o Estado e o patronato. Com abertura de alguns espaços de participação definidos pela nova Constituição e influenciada por certo ideário "neocorporativista" ${ }^{5}$ de inspiração europeia, assumia a representação dos

\footnotetext{
${ }^{5}$ Offe (1989) entende por "neocorporativismo: ao mesmo tempo em que é atribuído "status público" aos grupos sociais organizados, busca manter certa dose de controle estatal sobre o seu funcionamento com vistas a tornar cooperativa e previsível a relação entre Estado e os interesses organizados das classes.
} 
trabalhadores na participação, ao lado de entidades patronais e setores do Estado, em arenas de decisão, formulação e a gestão das políticas públicas em uma clara mudança em relação a sua postura de autonomia e antiestatal da década anterior. Em síntese, passava da "CUT-Movimento" para a "CUT-Instituição" (Alves, 2000; Galvão, 2012; Ladosky, 2014; Ricci, 2013).

\section{Os agricultores familiares entre duas organizações sindicais e a sub-representação dos assalariados}

Nos esforços para unificar o sindicalismo de trabalhadores rurais, em meados da década de 1990, ocorreram eventos marcantes que mostravam o potencial que a união das organizações do campo (DNTR/CUT, Contag, MST, MAB, entre outros) e a nova postura propositiva poderiam ter, como a construção dos Gritos da Terra Brasil (a partir de 1994), uma forma de mobilização anual, unifica e massiva de âmbito nacional e com objetivo de propor e negociar políticas com os governos; a participação da CUT e Contag na Comissão Técnica do Pequeno Produtor do Ministério da Agricultura (1993/94) para elaborar uma "política agrícola diferenciada" para este público, atingido pelo acordo do Mercosul; a conquista de políticas públicas de apoio à agricultura familiar, como o Programa Nacional de Apoio a Agricultura Familiar (Pronaf), em 1995; e a realização do ambicioso Projeto CUT/ Contag de Pesquisa e Formação Sindical (1996-1999) que visou repensar o projeto e a estrutura sindical rural (Grisa e Schneider, 2014; Picolotto, 2014b; Sabourin, 2017).

Esse conjunto de ações acabou redefinindo o projeto sindical da CUT/Contag e deu certo direcionamento de suas atenções e interpelações do Estado para o público da agricultura familiar. A formulação do Projeto Alternativo de Desenvolvimento Rural Sustentável (PADRS), com base nas elaborações do Projeto CUT/Contag de Formação Sindical, ocupou o centro das iniciativas sindicais na segunda metade da década de 1990. No VII Congresso da Contag (realizado 
em 1998), foram aprovados os seus contornos centrais: a luta por reforma agrária como forma de romper com o modelo de desenvolvimento excludente, concentrador de terra, renda e poder, e para expandir e consolidar a agricultura familiar; a opção pelo modelo da agricultura familiar que, além de propiciar desenvolvimento mais descentralizado, democrático, pode produzir alimentos com menores custos e danos ambientais, além de reduzir o êxodo rural; para os assalariados rurais, tratava-se de criar novos postos de trabalho, reduzir o desemprego e possibilitar melhores condições de vida e trabalho; criação de novas políticas sociais para o campo: educação, saúde, lazer, previdência e assistência social, formação profissional, pesquisa e assistência técnica etc.; e o repensar das relações de gênero e geração para valorizar os diversos sujeitos do campo (Contag, 1998).

Nas pautas anuais do Grito da Terra Brasil (1994-2015) que passou a ser o principal eventos anual de mobilização e 212 reivindicação do movimento sindical de trabalhadores rurais - percebe-se a presença constante, entre os principais temas, das demandas por política agrícola e reforma agrária para fortalecer a agricultura familiar. Como bem sintetiza Alberto Broch, presidente da Contag, referindo-se ao centro do seu projeto: "Nós queremos que ele se baseie no fortalecimento e na expansão da agricultura familiar, esse é o grande eixo, o grande eixo é fortalecer a Reforma Agrária porque se você tem a Reforma Agrária você expande, você fortalece a agricultura familiar" (informação verbal) ${ }^{6}$.

A busca por fortalecimento e ampliação da agricultura familiar passou a ocupar o centro do projeto da Contag, implicando uma mudança no eixo de poder interno. Se desde a sua fundação as pautas prioritárias foram a reforma agrária e os direitos trabalhistas, com lideranças nordestinas nos seus postos principais, com a entrada dos cutistas

${ }^{6}$ Alberto Broch, presidente da Contag entre 2009 e 2017, entrevista ao autor, em 2016. 
e adoção do PADRS, foi eleita a agricultura familiar como prioritária e lideranças sulistas passaram a ter maior destaque. $\mathrm{O}$ modelo da agricultura familiar adotado teve fortes contornos sulistas (Bonato, 2003): a de origem colona (pequenos proprietários de origem imigrante), modernizada, marcada pela perspectiva de integração aos mercados. Para ela, a principal demanda era crédito para produção, o que o Pronaf supriu (Picolotto e Medeiros, 2016).

Entretanto, essas novas orientações sindicais não foram unânimes entre os setores cutistas e nos anos seguintes causariam desacordos políticos internos e com antigos aliados. Setores cutistas descontentes com a unificação sindical e com a perspectiva de um sindicalismo propositivo deflagraram uma dissidência que daria origem ao Movimento dos Pequenos Agricultores (MPA). Da forma semelhante, o MST, que era próximo da CUT, discordou dessas novas perspectivas e passou a organizar, juntamente com o MPA, uma nova articulação de atores sociais do campo. Dessa articulação formou-se a seção brasileira da Via Campesina a partir do final da década de 1990 (Fernandes, 2004; Vieira, 2011). No âmbito sindical, ainda que a unificação na Contag tenha propiciado conquistas importantes, outras propostas cutistas não foram acolhidas provocando divergências nos anos seguintes. Dentre elas estiveram a adoção do pluralismo sindical e a flexibilização das formas de organização sindical de base que não foram aceitas em nome da preservação da unicidade.

A Contag e a CUT precisaram responder a essas divergências internas. A Feraesp, por exemplo, era uma organização específica da base da CUT e, com esta aliança, que visava tornar a Contag o principal instrumento de atuação cutista no campo, era natural que solicitasse sua filiação à confederação. Fez seu pedido de filiação para o VII Congresso da Contag de 1998, mas este foi recusado em nome da preservação da unicidade sindical. Como já existia uma federação (Fetaesp) e os STR que atuavam no estado, a maioria do 
congresso da Contag decidiu pela recusa do pedido de filiação (Medeiros, 2014).

Essas mesmas dificuldades e contradições motivaram uma dissidência sindical de agricultores familiares, na região Sul. Começou em Santa Catarina com a formação da Federação dos Trabalhadores da Agricultura Familiar de SC (Fetrafesc), criada em 1997, após tentativas frustradas de unificação sindical no estado. A Fetrafesc também solicitou filiação à Contag no Congresso de 1998, mas não foi aceita. Com essa negativa, fortaleceu a ideia de construir uma organização própria, alimentada pelo reconhecimento de que a agricultura familiar passava a ter no âmbito das políticas públicas e no debate acadêmico.

A emergência do agricultor familiar como personagem político na região Sul foi construída por diversas iniciativas das organizações sindicais e outros atores que criaram novos canais organizativos e fortaleceram sua identidade. A par-

214 tir de 1996 ocorreram diversas ações massivas de debates e organização desse público, como o Mutirão de Animação de Base em diversos municípios dos três estados; os Encontros Regionais da Agricultura Familiar, realizados uma vez por ano; e a constituição da Frente Sul da Agricultura Familiar, criada no encontro de 1999 para congregar diversos atores: sindicatos, cooperativas de crédito, leite, produção, associações diversas, segmentos de igrejas e ONG (Medeiros, 2014; Picolotto, 2014a).

Esse movimento organizado em favor do reconhecimento da agricultura familiar fez um trabalho de constituição da ideia-força agricultura familiar como identidade política. Como define Melucci (2001), a identidade política se constrói de forma relacional, nas demarcações de sentido com outros grupos. Para isso, o movimento apropriou-se da novidade que essa categoria representava, afirmou a especificidade de um segmento de agricultores que podiam ser chamados de familiares e construiu um projeto político de 
valorização do modelo de agricultura que estes exerciam (Picolotto, 2011; Picolotto e Medeiros, 2017).

Com o fortalecimento da dinâmica organizativa e da identidade da agricultura familiar na região Sul - aliado à percepção da falta de perspectiva de mudança na correlação de forças nas Fetags na região e na Contag - desenvolveu-se a ideia de construir uma organização sindical específica dos agricultores familiares de âmbito regional. Esse processo desaguou na fundação Fetraf-Sul no I Congresso Sindical da Agricultura Familiar, chamado para esse fim entre os dias 28 e 30 de março de 2001, em Chapecó-SC (Fetraf-Sul, 2001). Pouco tempo depois, com a criação de novas federações em São Paulo, Mato Grosso do Sul, Bahia e Minas Gerais, consolidava-se a dissidência e ganha maior corpo a ideia de formar uma organização nacional da agricultura familiar, o que ocorreu em novembro de 2005, durante o I Congresso Nacional da Agricultura Familiar, quando foi fundada a Fetraf-Brasil. O Congresso contou com delegados de 22 estados, "reunindo aproximadamente 1.000 sindicatos, representando mais de 500 mil famílias de agricultores e agricultoras" (Fetraf-Brasil, 2005, p. 6). Nos anos seguintes, a Fetraf-Brasil deslocou o centro político desse sindicalismo da região Sul para o âmbito nacional (Conti, 2016).

O processo de nacionalização da Fetraf também pode ser observado pela evolução de suas pautas anuais das Jornadas Nacionais de Luta da Agricultura Familiar (2005-2016). Até 2009 elas centravam-se em temas tradicionais dos agricultores do Sul, como crédito, renda, comercialização, dívidas e habitação rural. A partir de 2010, cresce a diversificação de demandas e de grupos representados. Ao lado de crédito e melhoria da renda aparecem reforma agrária, redução da pobreza, preservação ambiental e da biodiversidade, acesso à água e infraestrutura hídrica, respeito à diferença e à diversidade do Semiárido, sucessão rural e direito à liberdade de organização sindical. Essas demandas evidenciam que o 
modelo originário da agricultura familiar colona da Fetraf precisou ser repensado e complexificado, para abranger as necessidades de outros grupos de agricultores familiares de outras regiões. Se no Sul as bases são formadas fundamentalmente por setores relativamente consolidados de agricultores familiares com terra, em outros estados - como Pernambuco, Ceará, Pará, Goiás, Mato Grosso do Sul, Distrito Federal - as bases da Fetraf-Brasil são provenientes de assentamentos de reforma agrária e de setores da agricultura familiar menos capitalizados (Picolotto e Medeiros, 2016; Soares, 2016).

A criação de uma nova organização sindical de agricultores familiares confrontada com certo reposicionamento da Contag para dar maior espaço para essa mesma categoria produziu uma forte concorrência por bases, legitimidade e pelo formato da estrutura sindical rural. Enquanto o sistema sindical da Contag procurava manter unificada a representação formal de todas as situações de trabalho no meio rural (inclu216 sive os agricultores familiares), a Fetraf ergueu a bandeira da representação específica dos agricultores familiares, para isso procurou transformar os seus sindicatos ou construir novos na forma de Sindicatos de Trabalhadores na Agricultura Familiar (Sintraf), diferenciando-os dos STR da Contag.

No entanto, se as duas organizações direcionavam sua representação e seus projetos para a agricultura familiar, as demais categorias de trabalhadores rurais ficavam em segundo plano e geravam-se outros descontentamentos. Se nas décadas de 1970 e 1980 as polêmicas se davam pela sub-representação dos pequenos produtores na agenda sindical, a partir da década de 1990 a situação se inverte (Favareto, 2001; Medeiros, 2001). As principais dificuldades, apontadas nos documentos sindicais e relatos de lideranças, estão relacionadas à não priorização das demandas dos assalariados rurais nas pautas de reinvindicações apresentadas aos governos e à necessidade de criação de maiores espaços internos para aumentar a participação desses trabalhadores. 
Ao que pese a disputa entre organizações sindicais, o fato da direção da CUT ter dado certo apoio à criação da Fetraf (inclusive com a presença do presidente nacional na sua fundação) causou fortes questionamentos por parte da Contag, por esta também estar filiada à CUT. Afinal, como seria possível que duas organizações cutistas disputassem as mesmas bases? Qual deveria ser a organização prioritária?

Essa situação causou um debate no interior da Central sobre como deveria ser seu modelo organizativo no campo e como equacionar os conflitos. Diante dessa situação a CUT decidiu criar restrições quanto ao reconhecimento da Fetraf e sindicatos nos locais onde já atuavam as Fetag e sindicatos filiados (CUT, 2009). Passou a reconhecer federações e sindicatos específicos novos somente onde as organizações já existentes não fossem cutistas. Com isso, dava respaldo para a Fetraf (e também à Feraesp) se organizar nos estados em que as Fetag não eram filiadas à CUT (caso da região Sul e dos estados da Bahia, de São Paulo, de Minas Gerais, do Mato Grosso, entre outros), mas fechava a possibilidade de reconhecer sindicatos e federações que concorriam com organizações ligadas à Contag e que também eram filiadas à CUT (em estados do Nordeste e do Norte). Assim, referendava tanto a Fetraf (onde esta era mais forte) e a Feraesp (em São Paulo) quanto a parcela da Contag que era cutista. Tratou-se de uma fórmula para conciliar os interesses dos grupos das organizações, cedendo um pouco para cada um. Mas, com essa regra, ao mesmo tempo em que a Fetraf recebeu aval para atuar em diversos estados importantes, acabou não recebendo o reconhecimento da Fetraf-Brasil, pois atuava na base da Contag.

Essa disputa intestina na CUT levou à insatisfação de setores da Contag e à avaliação sobre a pertinência da continuidade de filiação da Contag na CUT, uma vez que a Central estava dando guarida à organização concorrente. O ápice desse processo levou à desfiliação da Contag da CUT no seu congresso 
nacional, em $2009^{7}$, movimento também influenciado pela fundação da Central dos Trabalhadores do Brasil (CTB), formada por dissidentes cutistas da Corrente Sindical Classista (CSC), ligada ao Partido Comunista do Brasil (PCdoB), somados à corrente Sindicalismo Socialista Brasileiro (SSB), associada ao Partido Socialista Brasileiro (PSB) e sindicalistas independentes (Medeiros, 2014). Filiaram-se à CTB diversas federações de estados importantes (dos três estados do Sul, Minas Gerais, Bahia, Mato Grosso, entre outros), alterando, assim, o jogo de forças interno na Contag. A independência das centrais seria escolhida como melhor caminho (Contag, 2009), ainda que continue com boas relações com as centrais em que as federações são filiadas (CUT e CTB).

Uma das principais divergências históricas entre os membros da CSC e da parcela hegemônica da Contag com a direção majoritária da CUT era a defesa, por esta última, da Convenção 87 da Organização Internacional do Trabalho, que recomenda a adoção do pluralismo sindical. $\mathrm{Na}$ visão desses setores, defensores da unicidade sindical, o pluralismo, ao estimular a criação de diferentes sindicatos, poderia dividir os trabalhadores e enfraquecer o movimento sindical (Corrêa, 2016; Galvão, Marcelino e Trópia, 2015).

\section{Disputas no campo jurídico: organizações "ecléticas" versus "específicas"}

A disputa entre as organizações sindicais desaguou no âmbito jurídico. Como os entes sindicais da Feraesp e da Fetraf não buscaram alcançar os registros sindicais ou tiveram dificuldades para obtê-los no Ministério do Trabalho - uma vez que este só admitia a categoria de sindicalização "trabalhador rural", inseparável - as Fetags de diversos estados (como as da região Sul, de Pernambuco e São Paulo) têm

7 Foram 1.441 votos favoráveis à desfiliação da CUT e 1.109 contrários (Rodrigues e Ladosky, 2015). 
questionado sua legalidade e suas ações de representação sindical. Alguns desses conflitos na justiça são elucidativos. Já no primeiro ano de existência, a Feraesp organizou uma grande greve de empregados do setor da cana na região de Ribeirão Preto: cerca de 58 mil trabalhadores param suas atividades por quinze dias. $\mathrm{O}$ setor patronal não aceitou negociar com os Sindicatos dos Empregados Rurais (SER) e a Feraesp, mas, sim, com a Fetaesp, federação reconhecida. A Feraesp e seus sindicatos entraram com um pedido de dissídio coletivo no Tribunal Regional do Trabalho de Campinas-SP, mas não obtiveram sucesso. O Tribunal considerou os SER e a Feraesp como "partes ilegítimas do processo, por lhes faltarem as condições legais de representação sindical” (Coletti, 1998, p. 225). Ao longo da década de 1990 ocorreram diversos outros conflitos judiciais pela representação da categoria dos empregados rurais e pelas verbas oriundas das contribuições sindicais, como sintetiza um documento: "à medida que novos Sindicatos de Empregados Rurais eram organizados, novos processos judiciais eram promovidos" (Feraesp, 2015, p. 19). A situação, aparentemente, só se alterou nos anos 2000, após longas disputas judiciais, quando a Feraesp foi reconhecida como representante legítima da categoria dos empregados rurais do estado de São Paulo, tendo inclusive obtido ganho de causa sobre as contribuições sindicais dessa categoria (Tribunal Regional do Trabalho da 2 ${ }^{a}$ Região, 2008). Entre os critérios que embasaram a decisão judicial destacam-se: "No atual momento do ordenamento jurídico brasileiro, há aprofundado prestígio à autonomia sindical e se incentiva a constituição de entidades por categorias econômicas ou profissionais específicas" (Tribunal Regional do Trabalho da $2^{\underline{a}}$ Região, 2008, p. 8, grifos nossos). Com a prevalência desse entendimento, a Feraesp, enquanto entidade específica, foi considerada a legítima representante dos "empregados rurais assalariados", portanto deveria receber as contribuições sindicais da categoria. 
A disputa foi similar entre os entes sindicais da agricultura familiar. No ano de 2003 as três federações do Sul deram entrada conjuntamente no Superior Tribunal de Justiça (STJ) em um Mandado de Segurança contra a inclusão da Fetraf-Sul e de seus sindicatos como organizações credenciadas pelo MDA para fornecer Declarações de Aptidão ao Pronaf, instrumento necessário para obter crédito e outros benefícios voltados à agricultura familiar. Alegavam que a área de atuação da Fetraf-Sul se sobrepunha às delas, o que feria a unicidade sindical e que ela não possuía Carta Sindical. Diante desse pedido, a ministra do STJ argumentou que apesar da Constituição de 1988 "vedar a criação de mais de uma entidade sindical representativa de categoria profissional ou econômica na mesma base territorial", esta também estabelece em seu art. 8 que "a lei não poderá exigir autorização do Estado para a fundação de sindicato" (Brasil, 2004, p. 4). Como a Fetraf-Sul foi devidamente constituída 220 por registro em Cartório, seria "mera formalidade a exigência do registro junto ao Ministério do Trabalho e Emprego" (Brasil, 2004, p. 5, grifos no original). Dessa argumentação, depreende-se a dubiedade da Constituição no que se refere à possibilidade de criação de novas organizações sindicais: determina que exista somente um sindicato por base territorial reconhecido pelo Ministério do Trabalho, mas permite que outros possam operar sindicalmente, embora sem registro sindical.

Essa situação não agrada as organizações sindicais estabelecidas e tem motivado diversos outros conflitos judiciais. Em 2009, no estado de Pernambuco, a Federação dos Trabalhadores na Agricultura (Fetape), ligada ao sistema Contag e filiada à CUT, moveu um processo judicial buscando a "nulidade de representação de categoria profissional da Fetraf, além do cancelamento do seu registro em cartório e da sua inscrição do CNPJ perante a Receita Federal" (Soares, 2016, p. 3). Em Santa Catarina, seguindo uma linha semelhante, a Fetaesc buscou "a nulidade da criação e a cessação 
da atividade como Federação da Fetraf-Sul" (Fetaesc, 2008), alegando que esta não tinha a Carta Sindical e era, na verdade, uma ONG. A lógica dos conflitos é similar nos municípios onde foram criados novos sindicatos específicos, seja de agricultores familiares, seja de assalariados rurais. O conflito de Graça Aranha, no Maranhão, é elucidativo. O STR local contestou a legalidade da existência de um Sintraf em sua base, alegando que este feria o princípio da unicidade sindical. O caso foi parar no Tribunal Superior do Trabalho (TST), donde se considerou que mesmo que a Constituição e a CLT estabeleçam que não possa coexistir dois sindicatos representativos de categorias idênticas na mesma base territorial, " não impedem o desmembramento de sindicatos com o objetivo de melhor representar diversas categorias que os integrem." (Brasil, 2010, p. 3, grifos no original). Ademais, acrescentam que "o desmembramento proporciona aos filiados maior identidade de interesses, pois se torna menos generalizado, em consonância com a regra de organização por categorias específicas" (Brasil, 2010, p. 3, grifos no original).

A partir da avaliação desses casos, pode-se considerar que, mesmo que os atores estabelecidos tenham utilizado recursos do campo jurídico para desqualificar e dificultar a atuação do ator desafiante, fica evidente nos casos relatados que o campo jurídico não é neutro e imutável na interpretação da legislação, conforme estabelece Bourdieu (2005). Está sujeito a mudanças, motivadas ou não por pressões externas na interpretação do direito. Nessa perspectiva, as decisões favoráveis à Fetraf, à Feraesp e aos seus sindicatos garantiram a essas federações certa segurança jurídica mediante as investidas dos adversários. Consolidavam-se, assim, suas posições no campo como representantes específicas dos agricultores familiares e dos assalariados rurais, respectivamente, enquanto as federações do sistema Contag seriam representantes ecléticas (genéricas) dos trabalhadores rurais em geral. 
Uma das consequências das disputas entre organizações sindicais e dos rebatimentos no campo jurídico é a consolidação do entendimento - com "jurisprudência fixada no Supremo Tribunal Federal, Superior Tribunal de Justiça e Tribunal Superior do Trabalho" (Contag, 2017, p. 71) - de que podem existir sindicatos específicos no interior de uma categoria eclética (como a de trabalhador rural), o que legitimou diversas iniciativas de divisão de sindicatos ou criação de novos por outros atores concorrentes.

\section{Categorias de sindicalização específicas: agricultores familiares e assalariados rurais}

O Ministério do Trabalho e Emprego criou, em 2011, o Grupo Especial do Trabalho Rural (Getru) para analisar a situação de concorrência política e de disputas judiciais e, ademais, avaliar as implicações sindicais da 222 Lei da Agricultura Familiar no ${ }^{-11.326}$, de 24 de junho de 2006, com o "possível surgimento de uma nova categoria" (Brasil, 2012, p. 1). O objetivo declarado do Getru foi alcançar "consensos" entre os diversos ministérios - do Trabalho, da Agricultura, do Desenvolvimento Agrário e do Desenvolvimento Social - com atuação na área e as organizações de representação sindical rural - Confederação da Agricultura e Pecuária (CNA), Contag e Fetraf (Brasil, 2012). Foi feito um levantamento sobre a legislação que regulamenta as políticas públicas para o âmbito rural, inclusive sobre o enquadramento sindical, mas não houve consenso sobre a pertinência de se constituir a categoria sindical trabalhador na agricultura familiar. Somente a Fetraf se posicionou favoravelmente ao entendimento de que a agricultura familiar tornou-se uma "categoria profissional diferenciada" com a Lei da Agricultura Familiar, pois passou a ter regulamento próprio, diverso ao dos demais 
trabalhadores rurais. Portanto, ao seu juízo, esta seria uma categoria específica passível de organização sindical própria.

Como o Getru de 2011 não chegou a produzir um relatório final por falta de consensos, o MTE criou e integrou um novo Grupo de Trabalho Rural em 2013, composto por centrais sindicais (CUT, CTB, Força Sindical, entre outras) e organizações sindicais da área (Contag, Fetraf e Feraesp), com o objetivo declarado de "estudar a realidade das relações de trabalho dos trabalhadores no âmbito rural, objetivando construir consensos para apresentação de propostas que definam a sua representação sindical" (Brasil, 2013, p. 59).

A forma de funcionamento desses grupos evidencia algumas características da sua composição e dos seus objetivos. Enquanto o primeiro grupo de 2011 foi composto por diferentes ministérios, com a participação da CNA e notória ausência da Feraesp, o segundo grupo de 2013 contou apenas com a presença do MTE pelo governo, das centrais sindicais e das diferentes organizações sindicais de trabalhadores do campo. Se o primeiro era mais plural por contar com representantes da CNA e de diversos ministérios, o segundo abrangeu mais organizações sindicais (centrais e Feraesp). Outra característica desses grupos foi a busca de consensos entre diferentes atores que concorrem entre si pelas bases sindicais e por recursos. Esse é um modelo de gestão do Estado em que as partes interessadas são chamadas para compor GT, estudar a situação e, juntas, decidirem o que será feito. Pode ser associado com a perspectiva do "neocorporativismo" (Offe, 1989) ou, mais especificamente, com a ideia de "Estado compromisso" (Vianna, 2007): o Estado convida as organizações de representação política para, juntos, arbitrarem a solução de um conflito, segundo a lógica estatal, ganhando o compromisso dos atores sociais com a solução encontrada.

Nessa perspectiva, no GT Rural de 2013, foram apresentados dados do Cadastro Nacional de Entidades Sindicais 
(CNES) reveladores dos conflitos existentes. Eles apontavam a existência de 117 sindicatos de assalariados rurais e dezesseis sindicatos regionais de agricultores familiares já com registro sindical, em sua maioria, por força de decisões judiciais e todos sem qualquer relação com a confederação reconhecida (Contag). Além desses, havia, em 2013, mais 324 pedidos de registro sindical de novas entidades específicas, aumentando para 600 pedidos em 2014 (Contag, 2017). Com base nisso e perante as demandas das organizações específicas (legitimadas pelas decisões judiciais), consolidou-se o entendimento em favor de uma nova normativa que redefinia a categoria de enquadramento sindical trabalhador rural do Decreto-Lei n⿳ 1.166 , de 1971, abrindo "a possibilidade de dissociação da categoria eclética de trabalhador rural nas categorias específicas de assalariados rurais e de agricultores familiares" (Brasil, 2014, p. 107, grifos nossos). Ou seja, abria-se a possibilidade legal da existência de mais 224 duas categorias de sindicalização independentes. Passam a coexistir a categoria eclética de trabalhador rural, composta pelos empregados rurais/assalariados e os agricultores familiares convivendo em um mesmo STR e Fetag; e as categorias específicas, agricultor familiar organizados nos Sintraf e Fetraf $^{8}$, e empregado rural/assalariado organizados nos SER e Feraesp (Feraesp, 2015, p. 16).

Essa norma criava espaços para todos os atores existentes, mas a situação atual não é de menor nível de disputa. Instaurou-se uma nova corrida por reconhecimento sindical no MTE, o que mobilizou diferentes legitimidades. A Contag afirma ter uma rede sindical de cerca de quatro mil STR, congregados em 27 federações em todos os estados e no Distrito Federal (Contag, 2017). Mas esses dados não

\footnotetext{
8 Desde 2011, busca firmar-se outra organização sindical, a Confederação Nacional de Agricultores Familiares e Empreendedores Rurais (Conafer), ligada à Força Sindical e fazendo um recorte de público sindical com base na linguagem da Lei da Agricultura Familiar ( $\mathrm{n}^{\circ}$ 11.326, de 2006).
} 
correspondem exatamente aos registros do CNES do MTE, que contabiliza 2.295 sindicatos filiados à Contag e 23 federações (Brasil, 2017a). Não constam registros de federações nos estados do Acre, Roraima, Amapá e no Distrito Federal. A distribuição das federações do sistema Contag e o número de sindicatos filiados podem ser visualizados no Gráfico 1.

\section{Gráfico 1}

Distribuição das federações do sistema Contag e sindicatos filiados

\section{Sindicatos Filiados}

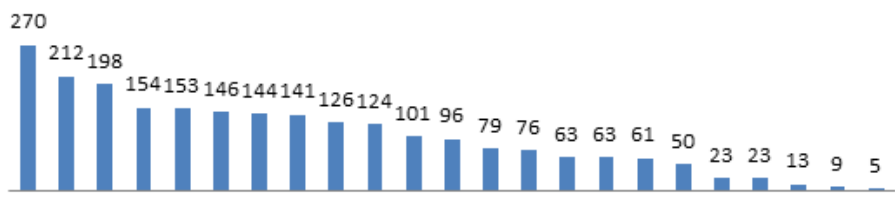

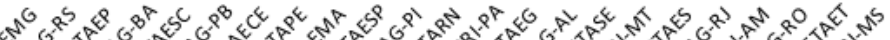
सेखिए

Fonte: CNES, Brasil (2017a).

A Fetraf também contesta os dados sobre a abrangência e formalização dos sindicatos contaguianos. Segundo seu coordenador nacional, Marcos Rochinski, um grande número de STR "não tem carta sindical ativa", porque está desatualizado, "ou porque não tem, mesmo, STR"; até mesmo algumas de suas federações estariam em situação irregular: "Então, também não é assim - 'ah, a Contag tem...' - que alguns deles ficam dizendo que - 'ah, a Fetraf é ONG' - e não sei o quê. Não é bem assim, não. O telhadinho deles é bem de vidro" (informação verbal) ${ }^{9}$.

Por sua vez, o sistema sindical da Fetraf está estabelecido em dezoito estados brasileiros, nos quais conta com federações estaduais, e afirma estar presente em

\footnotetext{
9 Marcos Rochinski é Coordenador Geral da Fetraf-Brasil desde 2013. Entrevista concedida ao autor, em 2016.
} 
cerca de mil municípios ${ }^{10}$. Organiza-se na forma de uma Confederação Nacional dos Trabalhadores na Agricultura Familiar, federações estaduais e sindicatos municipais ou microrregionais (Fetraf-Brasil, 2016). Nos últimos anos passou a pleitear seu reconhecimento como organização sindical da agricultura familiar. A Feraesp, de outra parte, além de estar organizada em São Paulo - onde afirma contar com setenta SER - esboçou um trabalho de criação de novas federações de assalariados rurais nos estados de Minais Gerais, Goiás, Mato Grosso do Sul, Pernambuco e Paraná para constituir "uma Organização Nacional da Categoria” (Feraesp, 2015, p. 23) ${ }^{11}$.

Atento a essa possibilidade e visando não dar espaços aos concorrentes, o sistema sindical da Contag vem discutindo esse tema desde o XI Congresso Nacional, de 2013, quando sugeriu que se estabelecesse uma regulamentação para os processos de dissociação de sindicatos (Contag, 226 2013). Ao perceber que estava perdendo bases para os adversários devido às dificuldades internas de aceitar mudanças na estrutura sindical, passou a orientar os seus sindicatos e federações com forte presença de assalariados que fizessem o processo de dissociação. Como declara Alberto Broch (presidente da Contag entre 2009 e 2017):

Nós começamos a compreender que o nosso sindicato é composto de mais de uma categoria. E quando você desassocia, você não quebra a unicidade. A unicidade você quebra se cria dois sindicatos da mesma categoria. Aí também teve uma parte complicada que ajudou muito, que foi a história da Feraesp em São Paulo, do Elio Neves, que criaram, lá, uma federação antiga e eles entraram na justiça

\footnotetext{
${ }^{10}$ Os dados do CNES não identificam a vinculação de Sintraf com a Fetraf, pois esta não é registrada no MTE.

11 Pelos dados do CNES, existem 49 sindicatos filiados à Feraesp (Ministério do Trabalho e Emprego, 2017a).
} 
contra a gente e começaram a ganhar as ações. E aí nós fomos vendo que, se a gente não criasse um movimento, ele ganhava as ações. Aí, ele ia para o Rio Grande do Sul e criava uma federação lá, ganhava as federações e eles iriam levar, digamos, os assalariados para um caminho de muito conflito, de muita briga. Se é isso, por que nós não vamos propor? (informação verbal) ${ }^{12}$.

Com essa nova orientação, a Contag está procurando se adaptar ao novo cenário, frear as dissidências e a excessiva fragmentação de sindicatos e, ao mesmo tempo, preservar seu papel de central camponesa, reivindicado desde os anos 1980. No entanto, essa posição é um tanto insegura para o momento atual. Continuar sendo uma organização de representação eclética em um cenário com outros atores específicos que ganham bases e dissociam categorias específicas aparenta não ser a melhor opção. Para se precaver e coerentemente com sua trajetória recente, o sistema sindical da Contag decidiu, em uma reunião de seu Conselho Deliberativo Extraordinário Ampliado, em 2014, "pela necessidade de estruturar dois sistemas sindicais autônomos e harmônicos" (Contag, 2017, p. 33). De um lado, optou por se manter na representação da agricultura familiar e, de outro, decidiu pela dissociação da categoria dos assalariados rurais por meio da formação de outro sistema sindical específico. Com essa decisão, após a formação de sindicatos e federações de assalariados nos estados, foi fundada a Confederação Nacional dos Trabalhadores Assalariados Rurais (Contar), durante o I Congresso Extraordinário dos Assalariados e Assalariadas Rurais, no dia 31 de outubro de 2015, em Brasília-DF.

As federações e os STR foram orientados a realizarem a opção pela representação de uma das categorias possíveis. Entre 2014 e o primeiro semestre de 2016, cerca de 560 STR

12 Entrevista concedida ao autor em 2016. 
fizeram a dissociação sindical e optaram por representar os agricultores familiares ou os assalariados rurais, e foram formados noventa novos sindicatos nessas mesmas bases para representar a categoria dissociada. No que se refere às federações estaduais, nesse mesmo período, optaram pela representação da agricultura familiar as dos seguintes estados: Ceará, Rio Grande do Norte, Piauí, Bahia, Pernambuco, Alagoas, Sergipe, Paraíba, Rio Grande do Sul, Santa Catarina, Paraná, São Paulo, Espírito Santo, Pará, Rondônia, Maranhão, Goiás, Tocantins e Distrito Federal; e optaram pela representação dos assalariados as dos estados do Rio de Janeiro e do Mato Grosso do Sul. Também foram fundadas federações específicas de assalariados rurais nos estados do Pará, Pernambuco, Goiás, Paraná e Rio Grande do Sul, que, juntas com as do Rio de Janeiro e do Mato Grosso do Sul, formam o sistema sindical da Contar (Contag, 2017; Contar, 2017).

A Contar foi criada para congregar os assalariados 228 rurais por uma dissociação pacífica dessa categoria do sistema Contag. Tal interpretação também é compartilhada pelo presidente da Contar, Antônio Lucas, (ex-secretário de Assalariados Rurais da Contag, entre 2005 e 2013), que acrescenta outros elementos que dão sentido para a existência de uma estrutura sindical autônoma:

Eu acho que quando nós apresentamos aquela pauta [da 1a Marcha dos Assalariados Rurais em Brasília, em 2012, quando, em sua ótica, o governo não soube lidar com as reinvindicações dos assalariados rurais e os confundiu com agricultores familiares], o mundo parece que se abriu para nós, para pensar assim: "Olha, nós precisamos de uma entidade cada dia mais específica. Nós precisamos ter entidade específica de agricultor familiar, para lidar com a pauta deles, e nós precisamos ter a nossa pauta específica e nossas entidades específicas”. [...] Não é briga interna; não é porque a Contag não vinha representando. A Contag representava. 
Mas quem representava eram os agricultores familiares.

Essa direção da Contag, aqui, é de agricultor familiar. [...]

Representando assalariado? Como? (informação verbal) ${ }^{13}$.

A representação dos interesses dos assalariados, segundo essa leitura, não poderia ser realizada a contento por lideranças majoritariamente provenientes da agricultura familiar. Pois, nos momentos decisivos, essas lideranças tenderiam a dar maior atenção para os interesses de sua categoria de origem, o que causava descontentamento para os assalariados. Esse é um elemento importante que reforçou as justificativas para criar uma estrutura sindical independente dos assalariados rurais.

Após a criação da Contar, a Contag afirmou ter feito uma alteração estatutária e de sua nomenclatura oficial em reunião do seu Conselho Deliberativo, ocorrida em 8 de março de 2016, passando a requerer a representação específica da categoria dos agricultores familiares (Contag, 2017). Desde então, foi nomeada formalmente como Confederação Nacional dos Trabalhadores Rurais Agricultores e Agricultoras Familiares (mantendo a sigla Contag), mas ainda não abriu mão da representação eclética dos trabalhadores rurais (Brasil, 2017b) ${ }^{14}$.

Nesse quadro, também a Fetraf tem revisto algumas de suas opções anteriores de auto-organização sindical, sem registro formal no Ministério do Trabalho. Nos estados do

\footnotetext{
13 Antônio Lucas é presidente da Contar desde 2015. Entrevista ao autor, em 2016.

${ }^{14}$ O MTE publicou a aceitação do pedido de Alteração Estatutária da Contag e da sua nominação em 17 de março de 2017. No entanto, a representação estatutária foi mantida nos termos da Carta Sindical de 5 de fevereiro de 1964: "Coordenação das entidades a ela filiadas que tenha representação da Categoria Profissional dos Trabalhadores e trabalhadoras rurais os assalariados e assalariadas rurais, empregados permanentes, safristas e eventuais na agricultura, criação de animais, avicultura, hortifruticultura e extrativismo rural, e agricultores e agricultoras, que exerçam suas atividades individualmente ou em regime de economia familiar, na qualidade de pequenos produtores, proprietários, posseiros, assentados, meeiros, parceiros, arrendatários, comodatários e extrativistas na base territorial Nacional" (Brasil, 2017b, p. 53).
} 
Sul está dissolvendo a Fetraf-Sul (de âmbito regional) e consolidando federações estaduais desde 2014. A partir desse momento, empenha-se em obter o registro das suas federações e sindicatos como representantes específicos dos agricultores familiares. Nessa perspectiva, a Fetraf-Brasil aprovou, no seu IV Congresso Nacional de 2016, a criação de um Sistema Confederativo da Agricultura Familiar para reforçar sua estrutura nos estados e municípios, e mudou sua denominação para Confederação Nacional de Trabalhadores e Trabalhadoras na Agricultura Familiar - Contraf (FetrafBrasil, 2016). Essas mudanças, segundo relato de seu coordenador geral, Marcos Rochinski, deveram-se à busca do registro sindical como confederação da agricultura familiar, e também porque "se apresentar como confederação tem um peso maior, do ponto de vista político. Seja na relação com o governo; com a sociedade" (informação verbal) ${ }^{15}$. Além do mais, seu IV Congresso Nacional também aprovou 230 uma resolução em que solicita à CUT o imediato acolhimento da sua filiação, visto que essa é a única confederação sindical da agricultura familiar vinculada à Central.

Da parte da Fetraf (agora Contraf), a busca do registro no Ministério do Trabalho e da filiação à CUT está relacionada à obtenção de maior segurança jurídica e política de sua posição enquanto ente sindical (preocupação que teria crescido com a mudança no governo federal), e combater o discurso dos sindicatos e federações do sistema Contag que acusam suas estruturas locais de serem clandestinas ou ONG. Ocorre que tanto a Contag quanto a Contraf estão realizando processos de adequação formal e pedidos de registro de sindicatos, federações e confederações sindicais dos agricultores familiares. As duas desencadearam uma corrida pelos registros sindicais e seu resultado pode reordenar o sindicalismo no campo.

15 Entrevista ao autor em 2016. 
Diante dessa situação de concorrência, cabe questionar: quais serão os critérios possíveis para dirimir conflitos pelas mesmas bases em um cenário em que existem organizações que se sobrepõem? Os contaguianos afirmam que, pelo critério de antiguidade e de organização enraizada em todos os estados, terão a prerrogativa de representar a agricultura familiar no país. Os fetrafianos afirmam representar a agricultura familiar de forma específica há mais tempo, que o sistema sindical da Contag optou por esse público apenas nos últimos anos e que a Contag continuou sendo uma organização eclética por seguir representando os trabalhadores rurais em geral (citam exemplos de onde não ocorreu a dissociação de uma das categorias). Na categoria dos assalariados as disputas também podem emergir em termos semelhantes, caso a Feraesp tenha sucesso no estabelecimento de sindicatos e federações concorrentes nos estados de atuação da Contar. O futuro do sindicalismo rural dependerá do desenrolar dessas disputas.

\section{Considerações finais}

Este trabalho apresentou um panorama das transformações no sindicalismo nas últimas décadas, relacionadas à acirrada disputa por representação, à criação de novas organizações sindicais e à fragmentação da representação política dos trabalhadores do campo. Trata-se de um processo de disputa que opõem diferentes organizações de representação de trabalhadores, mas que, em regra geral, convergem em termos de reivindicações e projetos políticos.

Com base nesta reflexão, pode-se constatar que a estrutura sindical dos trabalhadores rurais não foi capaz de representar satisfatoriamente a diversidade de interesses e de grupos existentes no campo. Desde a década de 1980, emergiram diversos atores sociais questionando a forma corporativa de representação e construindo novos canais de organizativos, seja optando por constituir movimentos (como MST, 
MAB e, nos anos 1990, o MPA) relativamente independes dos canais sindicais, seja formando novas estruturas sindicais (como DNTR, Feraesp, Fetraf, Contar). Como resultado desse processo, criou-se uma situação em que, mesmo mantido o discurso de defesa da unicidade sindical por parte da Contag, a situação atual da representação do conjunto dos trabalhadores rurais (sejam eles agricultores familiares, assalariados, sem-terra etc.) mostra a pluralidade de atores concorrendo entre si. Cada ator representa um grupo ou categoria social e tem determinados alinhamentos políticos e sindicais. Com essa nova condição de concorrência entre atores, foi enfraquecida a forma de representação corporativa tradicional do sindicalismo dos trabalhadores rurais e, por consequência, ocorreu certa perda de poder da organização estabelecida, comparando-se com épocas precedentes.

Com o acirramento da concorrência entre atores nos últimos tempos, os desdobramentos dos conflitos judiciais 232 e as novas normativas do MTE tem se consolidado o entendimento favorável à existência e reconhecimento das organizações sindicais específicas dentro da categoria eclética de trabalhador rural. Nesse cenário, a situação da Contag - que sempre teve o monopólio formal da representação da categoria - tornou-se insegura. Continuar sendo uma organização de representação eclética, uma espécie de central sindical camponesa, não parece ser mais a melhor opção, tendo em vista que a Fetraf e a Feraesp podem estar recebendo o reconhecimento do MTE para representar as categorias específicas dos agricultores familiares e dos assalariados rurais, respectivamente. Desde 2014, o sistema sindical da Contag vem realizando mudanças com vistas a se recolocar no campo, dissociando a categoria dos assalariados rurais, criando o sistema sindical da Contar e optando pela representação dos agricultores familiares. Nessa nova condição, Contag e Contar estão batendo de frente com as organizações sindicais que já representavam especificamente essas 
categorias, como a Fetraf e a Feraesp. Essa situação de organizações específicas concorrendo pelas mesmas bases e requerendo os registros no MTE ainda está indefinida. Seus desdobramentos definirão os rumos da representação sindical rural.

Por fim, ao avaliar o que restou da herança corporativa no sindicalismo de trabalhadores rurais, constata-se o seguinte: 1) mesmo com a manutenção da unicidade sindical como princípio constitucional, a realidade do campo evidencia a concorrência de organizações pelas mesmas bases, o que caracteriza uma situação de pluralidade sindical; 2) o registro prévio no MTE não é obrigatório, mas dá maior segurança e reconhecimento formal para as organizações sindicais, especialmente em momentos de disputas com outras organizações e de dificuldades de diálogo com os governos; 3) as contribuições sindicais obrigatórias foram extintas com a Reforma Trabalhista de 2017. Essa medida afeta especialmente os sindicatos de assalariados rurais, no momento em que estão constituindo sua estrutura nacional. Mas, entre os agricultores familiares, não terá muita consequência, uma vez que as contribuições já eram voluntárias. Portanto, dos pilares centrais do corporativismo, mantêm-se com certa força legal apenas a unicidade e o registro sindical no MTE, este último considerado facultativo.

\section{Everton Lazzaretti Picolotto}

é doutor em Ciências Sociais pelo CPDA/UFR-RJ, professor do Departamento de Ciências Sociais e dos Programas de Pós-Graduação em Ciências Sociais e em Extensão Rural da Universidade Federal de Santa Maria (UFSM).

\section{Bibliografia}

ALVES, Giovanni. 2000. Do "novo sindicalismo" à "concertação social": ascensão (e crise) do sindicalismo no Brasil (1978-1998). Revista de Sociologia e Política, n. 15, pp. 111-124.

ARAÚJO, Angela. 2002. Do corporativismo ao neoliberalismo. São Paulo:

Boitempo. 
ARAÚJO, Angela; TÁPIAS, Jorge. 1991. Corporativismo e neocorporativismo: exame de duas trajetórias. Boletim Informativo e Bibliográfico de Ciências Sociais, n. 32, pp. 1-30.

BOBBIO, Norberto. 1998. Dicionário de política. 11. ed. Brasília: Editora UnB.

BOITO JÚNIOR, Armando. 1991. O sindicalismo brasileiro nos anos 80. Rio de Janeiro: Paz e Terra.

Bonato, Amadeu. 2003. O Deser na história das organizações da agricultura familiar da região Sul. DESER 15 anos, ago. 2003.

BOURDIEU, Pierre. 2005. O poder simbólico. 10. ed. Rio de Janeiro: Bertrand Brasil.

BRASIL. 1971. Decreto-Lei no 1.166, de 15 de abril de 1971. Diário Oficial da União, Brasília, DF, 16 abr. 1971. Disponível em: <https://bit. ly/2v8Po8r>. Acesso em: 25 jul. 2018.

.1998. Lei no 9.701, de 17 de novembro de 1998. Diário Oficial da União, Brasília, DF, 18 nov. 1998. Disponível em: <https://bit. ly/2uOwvXA>. Acesso em: 18 jul. 2018.

. Superior Tribunal de Justiça. 2004. Mandado de Segurança no 2003/0212224-0. Diário Oficial de Justiça, Brasília, DF, 17 dez. 2004.

. Tribunal Superior do Trabalho. 2010. Processo $n^{\circ}$ TST-RR-136300-25.2009.5.16.0020. Brasília, DF: TST. Disponível em: $<$ https://bit.ly/2zSQxpu>. Acesso em: 18 jun. 2018.

. Ministério do Trabalho e Emprego. 2012. Nota Informativa $n^{\circ}$ 90/2012 CGRS/SRT/MTE: relatório do Grupo Especial do Trabalho Rural. Brasília, DF: MTE.

. Ministério do Trabalho e Emprego. 2013. Portaria no 005 , de 10 de julho de 2013. Diário Oficial da União, Brasília, DF, 11 jul. 2013. p. 59. 2014. Nota Técnica nº 88. In: . Ministério do Trabalho e Emprego. Manual de Procedimentos de Registro Sindical. Brasília, DF: MTE. 2017a. Portal de informações sobre relações do trabalho: cadastro nacional de entidades sindicais. Ministério do Trabalho, Brasília, DF. Disponível em: <https://bit.ly/2us11Go>. Acesso em: 29 dez. 2017. . Ministério do Trabalho e Emprego. 2017b. Pedido de alteração estatutária. Diário Oficial da União, Brasília, DF, n. 53, 17 mar. 2017. Seção 1.

CARDOSO, Adalberto Moreira. 2003. A década neoliberal e a crise dos sindicatos no Brasil. São Paulo: Boitempo.

CENTRAL ÚNICA DOS TRABALHADORES. 2009. Resoluções do $10^{\circ}$ Concut. São Paulo: CUT. 
COLETTI, Claudinei. 1998. A estrutura sindical no campo. Campinas: Editora Unicamp.

CONFEDERAÇÃO NACIONAL DOS TRABALHADORES ASSALARIADOS E ASSALARIADAS RURAIS. 2017. Federações filiadas. Contar, Brasília, DF. Disponível em: <https://bit.ly/2uq0zcH >. Acesso em: 20 maio 2017.

CONFEDERAÇÃO NACIONAL DOS TRABALHADORES NA

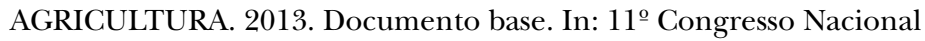
de Trabalhadores Rurais, Brasília. Anais... Brasília, DF: Contag. 2017. Documento Base e Plano de Lutas. In: 12 Congresso Nacional dos Trabalhadores Agricultores e Agricultoras Familiares, Brasília. Anais... Brasília, DF: Contag. 1998. Anais do VII Congresso Nacional dos Trabalhadores Rurais. Brasília, DF: Contag. 2009. Anais do X Congresso Nacional dos Trabalhadores Rurais. Brasília, DF: Contag.

CONTI, Irio Luiz. 2016. Organizações sociais e políticas públicas: inserção da Fetraf-Sul nas políticas públicas de segurança alimentar e nutricional. Tese de Doutorado em Desenvolvimento Rural. Porto Alegre: UFRGS. CORRÊA, Ellen Gallerani. 2016. Tendências recentes do sindicalismo rural no Brasil (2003-2014). In: VII Seminário Nacional de Sociologia e Política, Curitiba. Anais... Curitiba: UFPR.

DOMINGUES, José Maurício. 2007. Os movimentos sociais latinoamericanos: características e potencialidades. Análise de Conjuntura OPSA, n. 2, pp. 1-12.

FAVARETO, Arilson. 2001. Agricultores, trabalhadores: estudo sobre a representação sindical dos agricultores familiares brasileiros organizados na CUT. Dissertação de Mestrado em Sociologia. Campinas: Unicamp. 2006. Agricultores, trabalhadores: os trinta anos do novo sindicalismo rural no Brasil. Revista Brasileira de Ciências Sociais, v. 21, n. 62, pp. 27-44.

FEDERAÇÃO DOS EMPREGADOS RURAIS ASSALARIADOS DO ESTADO DE SÃO PAULO. 2015. Informativo Feraesp: Feraesp realiza seu sétimo congresso com a participação de 600 trabalhadores. São Paulo: Feraesp. FEDERAÇÃO DOS TRABALHADORES NA AGRICULTURA FAMILIAR DA REGIÃO SUL. 2001. Resoluções do I Congresso Sindical da Agricultura Familiar. Chapecó: Fetraf-Sul.

FEDERAÇÃO DOS TRABALHADORES RURAIS AGRICULTORES DO ESTADO DE SANTA CATARINA. 2008. Fetraf-Sul na mira da lei: Fetaesc requer ação declaratória de inexistência da Fetraf-Sul. Florianópolis: Fetaesc. 
FEDERAÇÃO DOS TRABALHADORES E TRABALHADORAS NA AGRICULTURA FAMILIAR DO BRASIL. 2005. Resoluções do I Congresso Nacional da Agricultura Familiar. Brasília, DF: Fetraf. 2016. Documento base do IV Congresso Nacional dos Trabalhadores na Agricultura Familiar. Brasília, DF: Fetraf.

FERNANDES, Bernardo Mançano. 2004. Questões da Via Campesina. Presidente Prudente: Núcleo de Estudos, Pesquisas e Projetos da Reforma Agrária.

GALVÃO, Andréia. 2012. De "laboratório" das relações de trabalho a formulador da política nacional: o Sindicato dos Metalúrgicos do ABC Paulista. In: SOUZA, Davisson Cangussu; TRÓPIA, Patrícia Vieira. Sindicatos metalúrgicos no Brasil contemporâneo. Belo Horizonte: Fino Traço, pp. 135-161.

GALVÃO, Andréia; MARCELINO, Paula; TRÓPIA, Patrícia Vieira. 2015. As bases sociais das novas centrais sindicais brasileiras. Curitiba: Appris. GOLDIN, Adrián. 2013. Corporativismo, neocorporativismo y libertad sindical. Derecho Laboral, v. 50, n. 247, pp. 451-472.

GRISA, Catia; SCHNEIDER, Sergio. 2014. Três gerações de políticas públicas para a agricultura familiar e formas de interação entre sociedade e Estado no Brasil. Revista de Economia e Sociologia Rural, v. 52, 236 pp. 125-146. Suplemento 1.

LADOSKY, Mario Henrique. 2014. A CUT e a questão corporativa no Brasil. Revista Ciências do Trabalho, n. 3, pp. 121-151.

MEDEIROS, Leonilde Sérvolo. 1989. História dos movimentos sociais no campo. Rio de Janeiro: Fase.

2001. Sem-terra, assentados, agricultores familiares: considerações sobre os conflitos sociais e as formas de organização dos trabalhadores rurais brasileiros. In: GIARRACCA, Norma (org.). ¿Una nueva ruralidad en América Latina? Buenos Aires: CLACSO, pp. 103-128.

2014. O sindicalismo rural nas últimas duas décadas: mudanças e permanências. In: OLIVEIRA, Roberto Véras; BRIDI, Maria Aparecida; FERRAZ, Marcos (orgs.). O sindicalismo na era Lula. Belo Horizonte: Fino Traço.

MELUCCI, Alberto. 2001. A invenção do presente. Petrópolis: Vozes.

NOVAES, Regina Reys. 1991. Continuidades e rupturas no sindicalismo rural. In: BOITO, Armando (org.). O sindicalismo brasileiro nos anos 80. Rio de Janeiro: Paz e Terra.

1997. De corpo e alma: catolicismo, classes sociais e conflitos no campo. Rio de Janeiro: Graphia.

OFFE, Claus. 1989. A atribuição de status público aos grupos de interesse. In: OFFE, Claus. Capitalismo desorganizado. São Paulo: Brasiliense. 
PALMEIRA, Moacir. 1985. A diversidade da luta no campo: luta camponesa e diferenciação do campesinato. In: PAIVA, Vanilda (org.). Igreja e questão agrária. São Paulo: Loyola. pp. 43-51.

PICOLOTTO, Everton Lazzaretti. 2011. As mãos que alimentam a nação: agricultura familiar, sindicalismo e política. Tese de Doutorado em Ciências Sociais. Rio de Janeiro: UFRRJ. . 2014a. A formação de um sindicalismo de agricultores familiares no Sul do Brasil. Sociologias, v. 16, n. 35, pp. 204-236. . 2014b. Os atores da construção da categoria agricultura familiar no Brasil. Revista de Economia e Sociologia Rural, n. 52, pp. 63-84.

PICOLOTTO, Everton Lazzaretti; MEDEIROS, Leonilde Sérvolo. 2016. A representação política no sindicalismo rural: antigos e novos atores. In: XL Encontro Anual da Anpocs, Caxambu. Anais... Caxambu: Anfiteatro Hotel Glória, pp. 1-30.

2017. A formação de uma categoria política: os agricultores familiares no Brasil contemporâneo. In: BERGAMASCO, Sonia Maria Pessoa; DELGADO, Guilherme Costa. Agricultura familiar brasileira: desafios e perspectivas de futuro. Brasília, DF: Sead, pp. 344-368

PINTO, Luzia Alice Guedes. 1979. A Contag de 64 a 76. In: ARAÚJO, Braz de José. Reflexões sobre a agricultura Brasileira. Rio de Janeiro: Paz e Terra, pp. 121-159.

RICCI, Ruda. 2013. Lulismo: da era dos movimentos sociais à ascensão da nova classe média. Rio de Janeiro: Contraponto.

RODRIGUES, Iram Jácome. 2015. Trabalhadores e sindicalismo no Brasil: para onde foram os sindicatos? Caderno $C R H$, v. 28, n. 75, pp. 479-491.

RODRIGUES, Iram Jácome; LADOSKY, Mario. 2015. Paradoxos do sindicalismo brasileiro: a CUT e a ruralização da ação sindical. Lua Nova, n. 95, pp. 87-142.

RODRIGUES, Leôncio Martins. 1990. CUT: os militantes e a ideologia. Rio de Janeiro: Paz e Terra.

SABOURIN, Eric. 2017. Origens, evolução e institucionalização da política de agricultura familiar no Brasil. In: BERGAMASCO, Sonia; DELGADO, Guilherme. Agricultura familiar brasileira: desafios e perspectivas de futuro. Brasília, DF: Sead, pp. 263-269.

SCHMITTER, Philippe. 1974. Still the century of corporatism? Review of Politics, v. 36, n. 1, pp. 85-131.

SOARES, Luiz Felipe. 2016. Unidade versus pluralidade: a construção política da representação sindical da categoria agricultor familiar em Pernambuco. In: VII Encontro da Rede de Estudos Rurais, Natal. Anais... Natal: UFRN. 
TRIBUNAL REGIONAL DO TRABALHO DA 2ª REGIÃO. 2008. Acórdão $n^{\circ}$ 20080645660. São Paulo: TRT2.

VIANNA, Luiz Werneck. 1976. Liberalismo e sindicatos no Brasil. Rio de Janeiro: Paz e Terra. 2007. O Estado Novo do PT. Política Democrática, n. 18, pp. 1-9.

VIEIRA, Flávia Braga. 2011. Dos proletários unidos à globalização da esperança: um estudo sobre internacionalismos e a Via Campesina. São Paulo: Alameda. 
PLURALIDADE SINDICAL NO CAMPO? AGRICULTORES FAMILIARES E ASSALARIADOS RURAIS EM UM CENÁRIO DE DISPUTAS

\section{EVERTON LAZZARETTI PICOLOTTO}

Resumo: Este artigo analisa as mudanças na estrutura sindical dos trabalhadores rurais nas últimas décadas, marcadas pela emergência de novas identidades políticas que lutam pelo reconhecimento de sua diversidade e pela constituição de formas próprias de representação. Desde os anos 1980 têm ocorrido experiências iniciais de organizações de assalariados e pequenos agricultores por fora dos canais sindicais estabelecidos. No entanto, foi nos primeiros anos do século XXI que formou-se uma organização sindical própria de agricultores familiares que passou a competir com o sindicalismo da Confederação Nacional dos Trabalhadores na Agricultura (Contag) e, mais recentemente, a formação de uma Confederação Nacional de Assalariados Rurais (Contar), como representante exclusiva dos assalariados rurais. $\mathrm{O}$ artigo explora essas mudanças recentes na representação dos trabalhadores do campo, os conflitos de posição gerados e suas relações com o Estado.

Palavras-chave: Sindicalismo; Representação Política; Trabalhadores Rurais; Agricultura Familiar; Assalariamento Rural.

\section{UNION PLURALITY IN THE FIELD? FAMILY FARMERS AND PAID RURAL WORKERS IN A DISPUTE SETTING}

Abstract: This article aims to analyze the changes in the union structure of rural workers in recent decades, marked by the emergence of new political identities struggling for the recognition of their diversity and creation of forms of representation. Since the $1980 \mathrm{~s}$ there have been some initial organizational experiences of wage 
earners and small farmers outside the established trade union channels. However, it was in the early years of the twenty-first century that a separate union of family farmers was formed and started to compete with the unionism of the National Confederation of Agricultural Workers (Contag) and, more recently, the National Rural Salaried Confederation (Contar), as the exclusive representative of rural workers. The study aims to explore these recent changes in the representation of workers in the field, conflicts of position generated and their relations with the State.

Keywords: Syndicalism; Political Representation; Rural Workers; Family Farming; Rural Wage.

Recebido: 10/01/2018 Aprovado: 06/07/2018 